Canadian

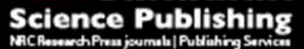

Canadian Journal of Civil Engineering Revue canadienne de génie civil

\title{
Design Philosophy and Requirements of Granular Wear Surface Thickness for Bridges Subjected to Extreme Truck Load
}

\begin{tabular}{|r|l|}
\hline Journal: & Canadian Journal of Civil Engineering \\
\hline Manuscript ID & cjce-2017-0023.R1 \\
\hline Manuscript Type: & Article \\
\hline Date Submitted by the Author: & 21 -May-2017 \\
\hline $\begin{array}{r}\text { Complete List of Authors: } \\
\text { Is the invited manuscript for } \\
\text { consideration in Special } \\
\text { Issue? : }\end{array}$ & N/A \\
\hline Keyword: & Gravel, Mechanistic Design, Mines, Wear Surface, Haul Truck \\
\hline &
\end{tabular}

SCHOLARONE ${ }^{\text {m }}$

Manuscripts 
1 Design Philosophy and Requirements of Granular Wear Surface Thickness for Bridges Subjected to Extreme Truck Load

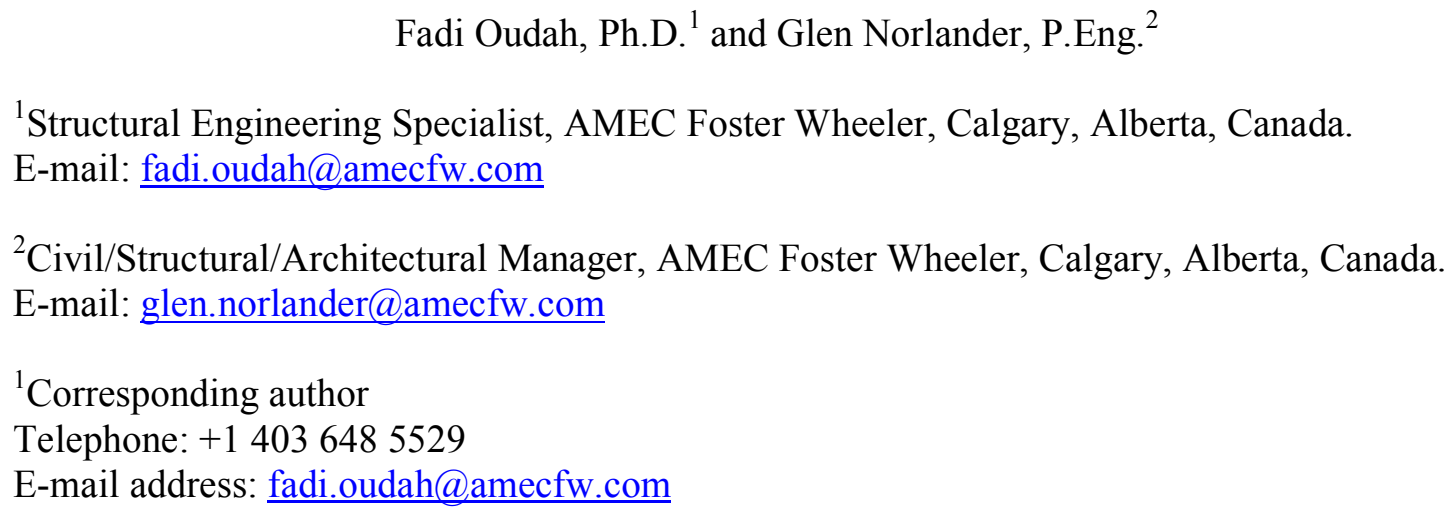

16 With the increasing demand to build bridge systems to transport extremely heavy trucks in 17 the mining industry, advancements in the current bridge design provisions are needed to 18 account for the extraordinary weight and configuration of the mining trucks. There are no 19 design provisions specifically developed to determine the granular wear surface thickness for 20 haul road bridges. This research study proposed a design philosophy for bridge gravel wear 21 surface design and developed a set of provisions for possible inclusion in international bridge and pavement codes. Three design requirements were developed, among which are two compulsory requirements and one optional requirement. The two compulsory design requirements include: Maintain gravel cohesion, and prevent concrete deck cracking during the passage of the design vehicle. The optional design requirement is: Minimize concrete deck cracking during the rare event of truck braking. Design recommendations and design-

27 aids pertaining to each design requirement based on detailed analytical modeling.

28 Keywords: Design Aids, Finite Element, Gravel, Mechanistic Design, Mines, Haul Truck,

29 Wear Surface 


\section{$30 \quad$ Introduction}

31 The growing demand to increase production while reducing cost in the mining industry

32 promotes the need to design and construct bridges that convey extremely heavy mine haul

33 trucks from the ore to the processing facility via the shortest route. In addition to designing

34 for extreme static and impact loads induced by these heavy trucks, determining the thickness

35 of the gravel wear coarse layer presents a major design challenge (Oudah et al. 2016; Oudah

36 and Norlander 2016). Maintenance of the gravel surfaced haul roads supporting haul trucks

37 requires frequent grading to sustain the original surface sections and profiles. This operation

38 would be somewhat dysfunctional should the gravel surface become discontinuous when

39 approaching the concrete deck of a bridge. In addition, a required depth of gravel over a

40 bridge deck is beneficial in limiting the concentration of wheel loading and thus reducing the

41 punching shear imposed on the concrete decks under the tires.

42 AMEC Foster Wheeler (AMEC FW) Oil and Gas Calgary Office has been involved in the 43 design of a bridge system subjected to extraordinary vehicle load at one of Alberta's Oil 44 Sands mines. The bridge transports the world's heaviest mining truck CAT 797 (> 600 ton).

45 Aside from the complex design of the $135 \mathrm{~m}$ three-span bridge, the design of the gravel wear 46 surface was a challenging task. Extensive literature review and consultation with bridge 47 experts were conducted to examine the principle design parameters of the bridge wear surface. The collected information with this regard revealed the following:

- Research regarding the response of bridges subjected to extreme load is scarce.

- North American design codes do not include guidelines regarding the design of gravel wear surface subjected to extreme load.

- Surveying haul road bridges in North America suggested that the current practice of wear surface thickness design is based on subjective judgement. 
54 Structural analysis of the bridge designed by AMEC FW indicated a significant contribution

55 of the total maximum bridge moment and shear was attributed to the wear surface self56 weight. For example, the contribution of the moment induced by the gravel weight varied 57 from $13 \%$ to $40 \%$ of the total design moment for a $250 \mathrm{~mm}$ and $1250 \mathrm{~mm}$ thick gravel layer, 58 respectively, when placed on a representative composite steel girder bridge configuration. It 59 was, therefore, decided to conduct a rational design procedure to suggest a wear surface 60 thickness that can provide a robust performance while imposing the smallest impact to the 61 overall moments and shears. The Special Structures group at AMEC FW Calgary Office 62 conducted a pioneering investigation to articulate the design philosophy for a bridge gravel 63 wear surface. Design aids were developed for bridge systems conveying extremely heavy 64 mining trucks for use in design and for possible inclusion in the North American Design 65 Codes (CSA-S6, AASHTO LRFD, and AASHTO). The design aids provide simple, yet 66 rational tools for design engineers in the mining industry.

\section{Literature Review}

\section{Haul Road Surface Construction Material}

69 Most mines do not use imported materials for haul road construction to minimize the 70 construction cost. Survey results also show that $82 \%$ of mines use crushed run of mine 71 (waste) for road surface, 36\% use crushed pit run gravel, while the remainder of mines use shale, plant coarse reject, crushed sandstone or other material (Tannant and Regensburg 2001).

The key parameters in selecting the road surface material are the road adhesion and rolling resistance factors (Thompson and Visser 2000). The former factor refers to the resistance acting between the road and tire, while the latter refers to the amount of drawbar pull or tractive effort required to overcome the retarding effect between the haul truck tires and the 
78 ground. Tractive effort is typically expressed in terms of percent road grade or in terms of 79 resistance force as a percentage of the Gross Vehicle Operating Weight (GVOW). A great 80 number of surface mining operations in North America are utilizing gravel since it offers a 81 stable roadway, when constructed and maintained properly, that resists deformation and 82 provides a relatively high coefficient of road adhesion, 0.55 to 0.85 (Kaufman and Ault 83 1977), and low rolling resistance, 2.0 to $2.7 \%$ of road grade (Tannant and Regensburg 2001).

84 Frequent road maintenance is required after a haul road surface is constructed. Most of the 85 maintenance consists of periodic grading to remove small ruts and potholes that are inevitably created by passing traffic (Collins et al. 1987; Thompson and Visser 2006).

\section{Mining Trucks}

88 The size and capacity of haul trucks used in surface mines has grown significantly over the 89 last decade from trucks capable of moving 20 tons of material to vehicles that transport as 90 much as 400 tons. Truck payload capacity follows the rapid advancement in tire technology

91 for larger trucks. A variety of haul trucks for ore and waste transportation are used by 92 different mines. The Oil Sand mines use the largest trucks, namely; CAT 777 (100 ton), CAT 93793 (240 ton), Komat'su 830E (240 ton), Komat'su 930E (320 ton or 340 ton), and CAT 797

94 (623 ton). Coal mines typically use trucks with smaller capacities, approximately 220 ton, 95 while smaller mining operations use trucks with payload capacities under 110 ton (Tannant 96 and Regensburg 2001).

97 Large haul trucks typically have two axles with four tires on the rear axle to provide better 98 manoeuvrability and a tighter steering radius. The design of tires is the limiting factor in the

99 design of larger haul trucks, as larger gross weights imply higher load per tire (reaching up to 100100 ton per tire). 


\section{Construction Practices versus Design Methods}

102 The design of haul roads has not advanced at the same rate as the rapid development in the 103 haul truck payload. Road-building technology from the early 70 s is still being practiced today 104 (Kaufman and Ault 1977). Haul road designs were entirely empirical until the early 1980s 105 when the California Bearing Ratio (CBR) cover thickness design technique emerged. Despite 106 the empirical nature of the technique, a mathematical approach to the calculation of the wear 107 surface thickness was derived. This conventional design approach characterizes the bearing 108 capacity of a given soil layer as a percentage of the bearing capacity of a standard-crushed 109 aggregate (Thompson and Visser 1996; Thompson 1996). The bearing capacity of each layer 110 is determined in accordance with ASTM D1883. The soil thickness is calculated based on the

111 wheel load and the soil CBR ratio. The CBR approach is simple, but it encounters numerous 112 disadvantages. The method assumes a constant elastic modulus for the layers of different 113 materials, although each material has its own engineering properties. It is based

114 fundamentally on empirical results applied to public roads subjected to a maximum axle load 115 of $80 \mathrm{kN}$.

116 Developments over recent decades have offered an opportunity for more rational-based and

117 rigorous haul road design procedures. The Mechanistic Design approach was developed 118 based on the theories of mechanics and relates the road structural behavior and performance 119 to traffic loading and environmental influences (Thompson and Visser 1997a; Thompson and 120 Visser 1997b). This method is a hybrid, for practicality purposes, in the sense that empirical 121 models are used to fill in the gaps that exist between the theory of mechanics and the 122 performance of the road. Finite Element (FE) layered elastic models are used to examine the 123 distribution of stress and strains within the soil layers in the Mechanistic design approach. 124 The vertical stress and strain are limited to predefined critical limits. The critical stress 125 corresponds to the ultimate compressive capacity of the gravel layer while the critical strain 
126 corresponds to the strain at which the gravel starts to loose structural integrity and degrades.

127 The modulus of resilience, required to define the elastic properties of the road material, can 128 be determined empirically using the AASHTO 1993 code, repeated load lab testing, or from 129 back-analysis of in-situ Falling Weight Deflectometer (FWD) testing.

\section{Design Philosophy}

131 The proposed philosophy of designing the thickness of the gravel wear surface subjected to 132 an extreme truck load is composed of fulfilling two compulsory requirements, and the 133 optional fulfillment of a third requirement;

134 - Compulsory requirement No. 1: Maintain gravel cohesion and integrity. This design

135 requirement is concerned with determining the minimum gravel dry density that will 136 prevent the loss of the gravel soil integrity under the combined action of tire load and 137 increased water content in the gravel layer.

138 - Compulsory requirement No. 2: Prevent concrete deck cracking during the passage of 139 the design vehicle. This design requirement is concerned with maintaining an un140 cracked concrete deck during the passage of the design vehicle at a constant speed 141 (i.e. primarily prevent punching shear of the concrete deck due to tire load).

142 - Optional requirement No. 3: Minimize concrete deck cracking during the rare event 143 of truck braking. Industrial traffic typically travels at a constant speed with a 144 predetermined frequency. No traffic jam or congestion is anticipated to occur in 145 industrial traffic. Braking of industrial traffic over the bridge would typically take 146 place in emergency events such as vehicle drifting. Depending on the site-specific 147 conditions and the bridge design criteria, the design engineers have to determine the 148 applicability of this design requirement and the necessity of implementing it in the 149 design of the bridge. This optional design requirement prevents excessive concrete 
deck cracking and ensures that the crack width is maintained below the bridge code design requirements during the braking event. Minimizing the concrete deck cracking, rather than preventing it from happening, was determined as an appropriate proportional response to the extreme rare event of vehicle braking.

154 The above mentioned design requirements were investigated analytically in this research. The

155 first design requirement was established using the Mechanistic Design approach. The second 156 and third design requirements were established via Finite Element simulation of the tire load 157 applied to a bridge wear surface. The detailed descriptions of the previously mentioned 158 approaches in relation to the design requirements are discussed in the following sections.

\section{Design Vehicle}

160 The work presented herein was conducted based on the vehicular characteristics of the CAT 161797 (Caterpillar 2013), which is typically used in Canada's Oil Sand mining industry. The 162623 ton haul truck represents the heaviest vehicle conveying ore and waste in Western 163 Canada. The configuration of the design vehicle is shown in Figure 1. The specified GVOW 164 of the two axle truck is 623 ton with a load per tire of 104 ton. The foot print area and tire pressure represent two important elements in the design of wear surface depth. The tires of the CAT797 truck (59/80R63), manufactured by Michelin or Bridgstone, have a foot print,

167 approximated as rectangle, of $1.15 \mathrm{~m} \times 1.5 \mathrm{~m}$ and an inflation pressure of $600 \mathrm{kPa}$. The high

168 tire pressure places great stresses on the road surface while the large foot print area induces a 169 stress bulb extending deep into the wear layer resulting in the need for a well-designed and 170 well-compacted surface layer with sufficient bearing capacity and stiffness. 


\section{Design Requirement No. 1: Maintain gravel cohesion and integrity}

172 The Mechanistic design approach was implemented to study the influence of varying both the

173 thickness and the dry density (or water content) of the wear surface on the gravel cohesion.

174 The fundamentals of this method, primarily used in the design of road pavement, are also 175 applicable for the design of a gravel layer placed on a bridge concrete deck. The method 176 controls the vertical stresses and strains in the gravel layer below critical limits. Two

177 parameters are controlled by the Mechanistic Design approach; compressive stress and 178 compressive strain in the gravel layer under the tire. The former parameter is concerned with 179 the bearing capacity of the soil while the latter is concerned with the cohesion of the soil. In 180 this context, cohesion is defined as the ability of the soil to maintain its integrity and it is 181 controlled by the strain and stress state in the gravel wear surface layer. If the stress and/or 182 strain exceed threshold values, the soil loses its cohesion and can no longer support the 183 vehicle weight. The results drawn from this analysis will be used to suggest a minimum 184 gravel dry density that is needed to sustain the functionality of the wear surface.

185 For well-compacted good quality gravel, the bearing capacity should not be a concern due to 186 the low compressive stress applied onto the gravel layer. In fact, test results indicate a stress 187 factor of safety around 6 for a typical crushed-aggregate surface layer (Tannant and 188 Regensburg 2001). An upper compressive strain limit of 0.002 is generally adopted for 189 design purposes while strains exceeding 0.0025 are usually associated with unacceptable 190 structural performance (Tannant and Regensburg 2001).

191 A comprehensive sensitivity analysis was conducted to examine the influence of several 192 design parameters on the variation of the vertical compressive strain in the gravel layer. The 193 following parameters were considered in the sensitivity analysis: Concrete deck thickness, 194 concrete compressive strength, gravel density, gravel layer thickness, and gravel-concrete 
195 deck interaction. The concrete deck thickness ranges between $500 \mathrm{~mm}$ and $600 \mathrm{~mm}$. The 196 concrete compressive strength ranges between $40 \mathrm{MPa}$ and $60 \mathrm{MPa}$. Three gravel dry 197 densities were considered; 98\% (target compaction level), 95\% and 92\%. The decrease in the 198 gravel dry density simulates the poor quality compaction or increase in water content. The 199 gravel layer thickness ranges between $200 \mathrm{~mm}$ to $1500 \mathrm{~mm}$. Unlike the conventional design 200 of haul mine design roads, the gravel layer is resting on top of a concrete deck in bridges.

201 Two extreme conditions were considered to simulate the gravel-concrete deck interaction;

202 Full adhesion and No adhesion. The former condition corresponds to the situation in which 203 the stresses are fully transferable between the gravel and the concrete deck, while the latter 204 corresponds to the situation in which there is no traction between the two layers. The latter 205 condition is also applicable when water is trapped between the concrete and gravel layer due 206 to poor drainage.

\section{Mechanistic Design Approach}

\section{Geometry and Boundary Conditions}

209 Two-D FE models were developed and used to examine the strain distribution as shown in 210 Figure 2. The gravel layer subjected to the tire load of the rear axle was considered in the FE

211 simulation since it represents the most critical region. Due to the symmetric nature of the 212 wheel loading about the longitudinal axes of the vehicle, only two tires were modeled. The 213 applied tire pressure was $600 \mathrm{kPa}$ based on the maximum tire inflation pressure of 59/80R63

214 tires used in CAT 797 trucks. The boundaries of the FE model extended for 1.0 times the 215 width of the tire measured from the outside edges of the tire foot print (Tannat and 216 Regensburg 2001). The width of the FE model was determined based on a sensitivity

217 analysis. The stress bulb vanishes near the side boundaries of the model, and hence, the 218 model implicitly accounts for the confinement effect. Mesh sensitivity analysis was 
219 conducted to optimize the mesh density. Fully integrated plane strain linear brick elements

220 were used in modeling the system.

221 In the Full adhesion FE model, both the gravel layer and the concrete deck were modeled

222 with a perfect bond at the gravel-concrete interface i.e. full transfer of stresses between the

223 two layers. The concrete deck was supported by roller supports. In the No adhesion FE

224 model, only the gravel layer was modeled and it was supported by roller supports to simulate

225 the sliding of the gravel layer over a stiff surface i.e. concrete deck.

226 Material Constitutive models

227 The modulus of elasticity, Poisson's ratio, and unit density were $330 \mathrm{MPa}$ (Tannant and 228 Regensburg 2001), 0.4 (Tannant and Regensburg 2001), and $2150 \mathrm{~kg} / \mathrm{m}^{3}$ (Van Wieren and 229 Anderson 1990), respectively, for the gravel layer. The modulus of elasticity of the concrete 230 deck was calculated as a function of the concrete compressive strength $4500 f_{c}^{1 / 2}$ (CSA-S6-

231 14). The Poisson's ratio and unit density of the concrete material were 0.2 and $2400 \mathrm{~kg} / \mathrm{m}^{3}$ 232 (Wight and MacGregor 2007), respectively.

\section{Results and Discussion}

234 Varying the thickness and the compressive strength of the concrete deck was found to have 235 negligible effect on the response of the models, and hence, their effect is not examined in the 236 remainder of this study. The decrease in the unit dry density of the gravel layer and the 237 concrete deck-gravel interaction have significant impacts on the system response. The 238 variation of the vertical compressive strain in the gravel layer as a function of the gravel layer 239 thickness and the gravel-concrete deck interface assumption are shown in Figures 3-5. Two 240 curves were plotted in each figure; with concrete deck (full adhesion with concrete) and 241 without concrete deck (no adhesion with concrete). Assuming that the applied stresses on the 242 gravel surface fully transfers to the concrete deck yields $33 \%$, on average, lower maximum 
243 vertical strain than if the no adhesion between the two layers was assumed. The no adhesion

244 with concrete curve represents the upper bound solution while the full adhesion represents the 245 lower bound solution to the problem. It is believed that the real behavior is somewhat in 246 between those two extreme boundary condition scenarios.

247 Requirement No. 1: Maintain gravel cohesion and integrity implies maintaining the strain 248 range, bounded by the extreme boundary condition scenarios, below the critical strain limit of 2490.002 . The strain range is lower than the critical strain limit in both the $98 \%$ and the $95 \%$ dry 250 density but higher than the critical strain for the $92 \%$ compaction. The change in the unit 251 density is manifested by the reduction of the gravel modulus of elasticity (an $8 \%$ drop in dry 252 density leads to a $37 \%$ drop in the gravel modulus of elasticity (Hopkins et al. 2007)). The 253 increase in the thickness of the gravel layer has a minor effect on decreasing the strain range.

254 The granular surface layer is recommended to meet the test requirements of MicroDeval loss 255 test to ensure durability requirements. Furthermore, high resistance to impact and abrasion is 256 a mandatory requirement for the selection and quality-control of the granular surface 257 material.

258 It was concluded that varying the wear surface thickness has a negligible influence on its 259 cohesion while the gravel unit dry density has the most significant impact on the response of 260 the system. Consequently, the Mechanistic design approach does not predict a minimum 261 gravel thickness. The wear surface granular layer is a manufactured product, and the water 262 contact can be typically controlled to achieve a minimum of $100 \%$ to $98 \%$ compaction level.

263 Nonetheless, severe weather conditions, poor drainage system, or poor bridge maintenance 264 may increase the water contact in the wear surface layer, which leads to a drop in the 265 compaction level. The analysis results suggest that the wear surface shall be compacted to at 266 least a $98 \%$ compaction level, while the dry density of the gravel layer should not drop 
267 beyond $95 \%$ of Standard Proctor maximum dry density at any time during the surface life of 268 the bridge.

269 Design Requirement No. 2: Prevent concrete deck cracking during the 270 passage of the design vehicle

271 A primary purpose of using a granular wear surface on the bridge deck is to distribute wheel 272 loads over a greater area in addition to providing continuity of surface with the haul road. 273 Load distribution is necessary to avoid areas of stress concentrations and punching shear 274 failure of the concrete deck due to elevated tensile stress within the concrete deck. Advances 275 in computational mechanics and in the computers available for performing the calculations 276 have greatly improved our ability to examine the road surface response under moving static 277 and dynamic vehicular load. Detailed FE analysis was conducted to determine the impact of 278 gravel thickness on the tri-axial stress state in the gravel layer and the concrete bridge deck. 279 Sensitivity analysis was conducted with regard to the concrete deck thickness, gravel layer 280 thickness, and concrete deck post-tensioning to develop design aids that server the purpose of 281 this design requirement.

282 Finite Element Approach

283 Geometry and Boundary Conditions

284 Representative FE models were developed using LS-DYNA software to examine the application of the tire load on the response of the gravel layer and the concrete deck. The geometry and the boundary conditions of the FE models are shown in Figure 6 and 7 respectively. The plane area of the FE models was $6 \mathrm{~m} \times 6 \mathrm{~m}$. The thickness of the concrete deck varied from $300 \mathrm{~mm}$ to $500 \mathrm{~mm}$, while the thickness of the gravel layer varied from 400 $\mathrm{mm}$ to $1500 \mathrm{~mm}$. The bridge girder spacing was $3 \mathrm{~m}$, which represents the typical girder spacing in bridges used to transport industrial traffic. The vertical translational degrees of 
291 freedom were constrained at two parallel lines at the deck soffit resembling the boundary 292 condition imposed by the bridge girders. Similarly, roller supports were positioned at the 293 transverse and longitudinal boundaries of the gravel layer in order to simulate the confining

294 effect of adjacent gravel volume. The concrete deck and the gravel layer were modeled using 295 constant stress solid elements with an hour glassing option. Mesh sensitivity analysis was 296 used to determine the optimum number of elements in the model.

297 The Michelin 59/80R63 tire consists of a tread, carcass, belts, bead, and wheel ring. Only the 298 tread, the belts, and the wheel ring were modeled since they control the stiffness and the response of the moving tire as shown in Figure 8. The wheel ring was modeled as rigid

300 elements. The tread belts, and wheel ring were modeled using Belytschko-Tsay shell 301 elements with two through-section integration points. The thicknesses of the tread, belt, and 302 wheel ring were $127 \mathrm{~mm}, 20 \mathrm{~mm}$, and $20 \mathrm{~mm}$, respectively, based on design specifications 303 (Bridgestone 2015). The truck was positioned in the middle of the gravel and concrete FE 304 models to produce the maximum bending on the concrete deck.

305 The interaction between the concrete and gravel layers was modeled as a surface-to-surface 306 contact with a coefficient of friction of 0.55 (Paikowsky et al. 2010). The coefficient of

307 friction of the tire-gravel interface was 0.35 (Noon 1994). The equivalent post-tensioning 308 stress applied to the concrete deck, as shown in Figure 7, is discussed in the Load Application 309 section.

\section{Material Constitutive Models}

311 The gravel was modeled using the Drucker-Prager material model. The model takes into

312 account the confining effect in enhancing the gravel capacity and enables the shape of the 313 surface to be distorted into a more realistic definition for soils. The gravel density was set to $3142200 \mathrm{~kg} / \mathrm{m}^{3}$ (CSA-S6-14). The elastic shear modulus, Poisson's ratio, and angle of friction 
315 were $69 \mathrm{MPa}, 0.25$, and $1.0122 \mathrm{rad}$ (Reid et al. 2004), respectively, while the cohesion value

316 was $0.05 \mathrm{MPa}$ (Wu and Thomson 2007).

317 The response of the gravel material model was validated using FE simulation against 318 experimental behavior of granular soils subjected to the tri-axial state of stress conducted by

319 Verdugo and Hoz (2006). Series of Isotropically consolidated drained (CID) triaxial 320 compression tests were conducted at confining pressures in the range of 200 to $600 \mathrm{kPa}$ on 321 samples with height/diameter ratio of 2. Tests were conducted in strain-controlled manner 322 with a deformation rate of $0.1 \% / \mathrm{min}$. The samples were prepared by the method of wet 323 tamping using distilled water in a proportion of $5 \%$ in weight, and were compacted to an 324 initial relative density of $70-80 \%$. The cylindrical samples were modeled using constant 325 stress solid elements with an hour glassing option using the above mentioned material 326 mechanical properties. The results of the FE gravel model are compared with the 327 experimental test results in Figure 9. The FE and experimental data were plotted in terms of 328 deviatoric stress versus axial strain. The stiffness, strength, and ultimate strain of the FE 329 simulation are, in general, in good agreement with the experimental test results. The Drucker330 Prager material model along with the assigned mechanical properties were, therefore, 331 validated against the mechanical response of compacted granular material under tri-axil state 332 of compressive stresses.

333 The concrete was modeled using the Winfrith Concrete Model, which is a basic plasticity 334 model that includes strain softening in tension, strain rate effects, and confining effects. The 335 assigned concrete density was $2400 \mathrm{~kg} / \mathrm{m}^{3}$ while the Poisson's ratio was 0.2 (Wight and 336 MacGregor 2009). The assigned concrete compressive strength was $60 \mathrm{MPa}$ and the modulus 337 of elasticity was $32.1 \mathrm{GPa}$ (CSA-S6-14). The material model was validated against the 338 response of concrete cylinders subjected to confining pressure as detailed in Schwer (2010). 
339 The tire tread was modeled as an elastic material with a density of $910 \mathrm{~kg} / \mathrm{m}^{3}$, modulus of 340 elasticity of $50 \mathrm{MPa}$, and Poisson's ratio of 0.3 (Reid 2001). The steel belt and the wheel ring

341 were modeled as elastic materials with a density of $7800 \mathrm{~kg} / \mathrm{m}^{3}$, modulus of elasticity of 200

$342 \mathrm{GPa}$, and Poisson's ratio of 0.3 (Reid 2001).

343 Load Application

344 Oudah and Norlander (2016) conducted extensive sensitivity analysis to examine the 345 dynamic response of bridge systems subjected to extremely heavy mining trucks. The 346 analysis results recommended a Dynamic Load Allowance (DLA) value of 0.19 for the 347 design of bridges conveying CAT 797 trucks. In this study, the specified GVOW of the CAT 348797 was factored up by $19 \%$ to account for the dynamic response of the moving vehicle over 349 the bridge surface. One-sixth of the factored GVOW was assigned to the wheel ring.

350 The wheel inflation and application of tire self-weight, gravel self-weight, concrete self351 weight, and transverse concrete post-tensioning were applied during the explicit dynamic 352 relaxation phase. The explicit dynamic relaxation phase is a transient analysis phase that 353 precedes regular transient analysis and is typically used to preload a model before onset of 354 transient loading. The explicit dynamic relaxation phase terminates and the solution 355 automatically proceeds to the transient analysis phase when the distortional kinetic energy is 356 sufficiently reduced, i.e. the solution undergoes a form of damping during this phase.

357 The wheel inflation was conducted using AIRBAG_SIMPLE_PRESSURE_VOLUME card 358 in LS-DYNA. The applied inflation pressure was calculated as follows:

$$
\text { Pr essure }=\beta \frac{C N}{\text { Relative Volume }}
$$


361 Relative Volume $=\frac{\text { Current Volume }}{\text { Initial Volume }}$

$362(2)$

363 The constant $C N$ was set to 0.00032 (Reid 2001), while the scale factor $\beta$ was set to unity.

364 The concrete deck is typically composed of concrete panels connected to each other and post-

365 tensioned longitudinally and transversely. Three scenarios were considered with regard to the 366 concrete deck post-tensioning; zero post-tensioning, post-tensioning with $12.7 \mathrm{~mm}$ 7-wire $3671860 \mathrm{MPa}$ strands spaced at $300 \mathrm{~mm}$ and post-tensioned to $70 \%$ at transfer, $12.7 \mathrm{~mm}$ 7-wire $3681860 \mathrm{MPa}$ strands spaced at $150 \mathrm{~mm}$ and post-tensioned to $70 \%$ at transfer. The former and 369 latter post-tensioning levels correspond to uniform stresses of $1 \mathrm{MPa}$ and $2 \mathrm{MPa}$, 370 respectively, applied uniformly on the transverse face of the concrete deck as shown in

371 Figure 7. The post-tensioning was applied during the explicit dynamic relaxation phase.

\section{Results and Discussion}

373 The results of the sensitivity analysis are presented in terms of design aids developed 374 specifically to facilitate a practical design procedure of the gravel wear surface in accordance 375 to the Design Requirement No. 2: Prevent concrete cracking during the passage of the design 376 vehicle. The design-aid diagrams in Figures 10-12 are illustrated in terms of the concrete 377 tensile stress level at the bottom of the concrete deck versus the thickness of the gravel layer.

378 Three figures were generated corresponding to the previously mentioned concrete deck 379 transverse post-tensioning scenarios. For each post-tensioning level, three concrete deck 380 thicknesses were considered; $400 \mathrm{~mm}, 450 \mathrm{~mm}$, and $500 \mathrm{~mm}$. Linear interpolation between 381 the figures is permitted should the desired post-tensioning level and/or the concrete deck 382 thickness do not fall within the ones included in the figures. 
383 The design curves shown in Figures 10-12 were developed based on the FE analysis results 384 and factored up for design purposes in accordance to the following procedure. The curves 385 were developed as the summation of the FE results and three standard deviations (FE $+3 \sigma)$.

386 The addition of three standard deviations to the mean value of the FE results establishes a 387 $99 \%$ level of confidence in the design of the gravel wear surface thickness, assuming a normal distribution of the FE results. This procedure accounts for the variance between the FE analysis results, given the assumptions adopted in developing the models, and the actual

390 behavior of concrete bridge decks. The variance corresponds to a coefficient of variation of 0.05 (Ellingwood et al. 1980). Thus, the $\mathrm{FE}+3 \sigma$ represents a more reliable measure for design purposes.

Based the proposed design-aids, design engineers shall follow the following steps in designing the thickness of the gravel wear surface to satisfy the Design Requirement No. 2:

1. Select the design post-tensioning level (graph ordinate).

2. Select the concrete deck compressive strength f'c.

3. Select the concrete deck thickness (graph abscissa).

4. The intersection of the inclined concrete deck thickness curve with the horizontal line

For example, for a $450 \mathrm{~mm}$ thick concrete deck, $60 \mathrm{MPa}$ concrete deck compressive strength, and $12.7 \mathrm{~mm}$ 7-wire $1860 \mathrm{MPa}$ strands spaced at $300 \mathrm{~mm}$ and post-tensioned to $70 \%$ at transfer (1MPa reaction stress), the minimum design gravel thickness that is needed to avoid cracking in the concrete deck under vehicle load is $450 \mathrm{~mm}$. 
405 Design Requirement No. 3: Minimize concrete deck cracking during the 406 rare event of truck braking

407 The concrete deck-wear surface-vehicle dynamic interaction during the braking event of CAT 408797 vehicle is a complex phenomenon due to the involvement of several influential 409 parameters in the dynamic response of the system. As such, advanced nonlinear Finite 410 Element simulation was conducted to examine the response behavior of the wear surface 411 gravel layer to fulfil the optional Design Requirement No. 3. The objective of the FE analysis 412 was to propose a gravel thickness design factor that satisfy the philosophy of the Design 413 Requirement No. 3. The design factor shall be applied to the gravel thickness determined 414 based on Design Requirement No. 2.

415 Typical configuration of concrete thickness, gravel thickness, and transverse post-tensioning 416 designed in accordance to the Design Requirement No. 2 (refer to design aids shown in 417 Figure 10-12) were considered in the FE simulation. The configuration has $450 \mathrm{~mm}$ concrete 418 deck, $500 \mathrm{~mm}$ gravel layer, and $1 \mathrm{MPa}$ equivalent transverse post-tensioning.

419 Finite Element Approach

420 Geometry and Boundary Conditions

421 The geometry and the boundary conditions of the FE braking model were similar to those 422 used in examining Design Requirement No. 2, except for the longitudinal dimension of the 423 concrete deck and the gravel layer. The length of the two layers were extended for $60 \mathrm{~m}$ as 424 shown in Figure 13.

\section{Material Constitutive Models}

426 The material constitutive models of the concrete deck, gravel wear surface, and tire were 427 similar to those used in conducting the FE analysis pertaining to Design Requirement No. 2. 
429 The concrete self-weight, gravel self-weight, tire load, and concrete deck transverse post430 tensioning were applied during the explicit dynamic relaxation phase. Additional pulse force 431 generated due to the tendency of the vehicle to overturn about its center of gravity, referred to 432 as the pitch effect, was applied in the proceeding transit dynamic phase. The pitch force was 433 calculated using simple mechanics given the dimensional properties of the vehicle, speed, and 434 surface friction. The pitch force was found to be 0.57 times the vehicle's weight distributed to 435 the front axle. The wheel ring was subjected to an initial translational velocity and angular 436 velocity about the rotational axis corresponding to the maximum truck speed $(18.8 \mathrm{~m} / \mathrm{s})$ in the 437 transit phase.

\section{Results and Discussion}

439 The FE braking model was first validated against a simple mechanics-based analytical 440 solution. Given the vehicle dimensions, mass, and tire-to-gravel friction, the braking 441 deceleration and distance were calculated as $5.4 \mathrm{~m} / \mathrm{s}^{2}$ and $32.6 \mathrm{~m}$, respectively, based on the 442 mechanics-based analytical solution. The percentage difference between the aforementioned 443 values and the ones obtained from running the FE braking model was $4 \%$ and $9 \%$ for the 444 braking deceleration and braking distance, respectively. Therefore, the FE braking model was 445 reasonably accurate in predicting the response of the gravel, concrete, and tire interactions.

446 Analysis results show a significant increase in the stress level at the deck soffit as illustrated 447 in Figure 14 for a travel time of 1 second. Snapshots of the braking event are also shown in 448 the figure for multiple time periods. The static stresses were increased by $110 \%$ at the peak 449 braking force. This is attributed to the fact that the dynamic impact force generated by 450 braking of the CAT 797 is approximately $114 \%$ times the static force. This elevated vertical 451 force is due to the pulse induced by the pitching effect on the front wheels. 
452 The gravel thickness and/or the concrete deck thickness required to maintain an un-cracked 453 concrete deck is extremely large in the event of vehicle braking. Preliminary results indicate a 454 minimum gravel thickness of $1850 \mathrm{~mm}$ required to maintain an un-cracked $500 \mathrm{~mm}$ thick 455 concrete deck. This extraordinary thick gravel layer will place tremendous dead weight on the 456 structure and results in significant material and construction costs even though the probability 457 of a truck braking hard over the bridge is extremely low. As such, the design criterion under 458 braking action is stated as follows:

459 Localized cracking at the bottom of the concrete deck is allowed to occur under the extreme 460 event of braking given that the crack width is maintained below the maximum crack width at 461 serviceability limit state specified by the bridge code CSA S6-14.

462 The maximum crack width permitted by CSA S6-14 for a prestressed concrete deck at the 463 serviceability limit state is $0.15 \mathrm{~mm}$ (Clause 8.12 .3 .1 ). Based on the strain gradient in the 464 concrete deck, the analysis results indicate a minimum gravel thickness of $700 \mathrm{~mm}$ to 465 maintain crack widths below the maximum limit. Thus, a design factor of 1.55 shall be 466 applied to the gravel wear surface thickness determined based on the Design Requirement

467 No. 2, if the design engineer decides to fulfil the optional Design Requirement No. 3.

\section{Conclusions and Design Recommendations}

469 In the absence of scientific-based studies for determining acceptable depths of a gravel wear 470 course over concrete bridge decks under heavy haul truck traffic, this article outlined a 471 detailed rational approach aimed at providing a basis to optimize the wear course layer 472 thickness. A design philosophy composed of satisfying two compulsory design requirements 473 and one optional design requirement was proposed. Advanced structural analysis including 474 Mechanistic design and nonlinear Finite Element modeling were conducted to develop design 
aids pertaining to the proposed three design requirements. The design requirements and the developed design aids are outlined as follows:

- Compulsory Design Requirement No. 1: Maintain gravel cohesion and integrity.

This design requirement is concerned with determining the minimum gravel dry density to maintain the integrity of the wear surface. The gravel layer shall be compacted to $98 \%$ of Standard Proctor maximum dry density. The water content shall not drop beyond $95 \%$ during the service life of the bridge.

- Compulsory Design Requirement No. 2: Prevent concrete deck cracking during the passage of the design vehicle.

This design requirement is concerned with maintaining an un-cracked concrete deck during the passage of the design vehicle at a constant speed. The design-aid diagrams shown in Figures 9-11 shall be used to determine the minimum gravel thickness.

- Optional Design Requirement No. 3: Minimize concrete deck cracking during the rare event of truck braking.

This requirement accounts for the behaviour of the bridge deck in the rare event of vehicle braking. The design engineers shall determine the applicability of this requirement based on the project-specific design criteria. A factor of 1.55 shall be applied to the gravel thickness determined based on Design Requirement No. 2.

The above-mentioned design philosophy and design requirements are recommended for consideration by the related code committees of the North American pavement and bridge design codes (CSA-S6, AASHTO LRFD, and AASHTO) to account for the increasing number of bridges designed to transport extremely heavy mining trucks. The design approach is rational-based and provides a simple tool for bridge engineers to design the thickness of bridge granular wear surface. 


\section{Acknowledgments}

500 The authors would like to acknowledge AMEC Foster Wheeler Oil and Gas Canada, Calgary

501 office for financial support toward this research project.

\section{References}

AASHTO. 1993. AASHTO Guide for Design of Pavement Structures. American Association of State Highway and Transportation Officials. Washington, D.C. USA.Bridgestone. 2015. Off-the-road tires for earthmovers brochure. http://www.bridgestone.com/products/speciality tires/index.html

AASHTO LRFD. 2012. AASHTO LRFD Bridge - Design Specifications. American Association of State Highway and Transportation Officials. Washington, D.C. USA.

Bridgestone. 2015. Truck tire data book. Version 15.1.

Caterpillar. 2013. Caterpillar CAT 797F specifications. Caterpillar, Inc., Peoria.

Collins, J. L., Fytas, K., and Singhal, R. K. 1987. Design, construction and maintenance of surface mine haulage roads. International Journal of Surface Mining, Reclamation and Environment, 1(2), 137-145.

CSA-S6-14. 2014. Canadian Highway Bridge Design Code, CSA, Mississauga, Ontario, Canada.

Ellingwood B. R., Galambos T. V., MacGregor J. G., and Cornel C. A. 1980. Development of a probability based load criterion for American National Standard A58. NBS Special Publication 577, National Bureau of Standards, U.S. Department of Commerce, Washington, D.C. USA. 
Hopkins T. C., Beckham T. L., and Sun C. 2007. Resilient Modulus of Compacted Crushed Stone Aggregate Bases. Kentucky Transportation Center in Cooperation with the Kentucky Transportation Cabinet, The Commonwealth of Kentucky, and Federal Highway Administration, KY, USA.

Kaufman, W. W. and Ault, J. C. 1977. The design of surface mine haul roads manual. USDOI Information circular 8758, USBM, pp. 2-7, 19-30.

Noon, R. K. 1994. Engineering analysis of vehicular accidents. CRC Press. USA

Oudah, F. and Norlander, G. "Dynamic load allowance factors for bridges subjected to extreme live loads," (Submitted to the Journal of Bridge Engineering, Jan 2016)

Oudah, F., Norlander, G. and El-Hacha, R. 2016 Live load factors for bridge systems transporting extremely heavy mine trucks. ASCE Journal of Bridge Engineering, doi:10.1061/(ASCE)BE.1943-5592.0000994.

Paikowsky S. G., Canniff M. C., Lesny K., Kisse A., Amatya S., and Muganga R. 2010. LRFD Design and construction of shallow foundations for highway bridge structures. National Cooperative Highway Research Program NCHRP, Report 651, 139 pp.

Reid J. D. 2001. Ls-Dyna example manual. Livermore Software Technology Corporation. CA, USA, $292 \mathrm{pp}$.

Reid J. D., Coon B. A., Lewis B. A., Sutherland S. H., and Murray Y. D. 2004. Evaluation of LS-Dyna soil material model 147. Report No. FHWA-HRT-04-094. Federal Highway Administration, US, $77 \mathrm{pp}$.

Schwer L. 2010. An introduction to the Winfrith concrete model. Schwer Engineering \& Consulting Services, $28 \mathrm{pp}$. 
542 Tannant D. D. and Regensburg. 2001. Guidelines for Mine Haul Road Design. 111 pp.

543 Thompson, R. J. 1996. The design and management of surface mine haul roads. Ph.D 544 dissertation. University of Pretoria.

545 Thompson, R. J., and Visser, A. T. 1996. An overview of the structural design of mine 546 haulage roads. The Journal of South African Institute of Mining and Metallurgy.

547 Thompson, R. J., and Visser, A. T. 1997. A mechanistic structural design procedure for 548 surface mine haul roads. International Journal of Surface Mining, Reclamation and $549 \quad$ Environment, 11(3), 121-128.

550 Thompson, R. J., and Visser, A. T. 1997. An introduction to the integrated design of surface 551 mine haul roads. International Journal of Surface Mining, Reclamation and $552 \quad$ Environment, 11(3), 115-120.

553 Thompson, R. J., and Visser, A. t. 2000. Selection parameters for mine haul road wearing 554 course materials. International Journal of Surface Mining, Reclamation and $555 \quad$ Environment, 14(1), 1-17.

Thompson, R. J., and Visser, A. T. 2006. Selection and maintenance of mine haul road 557 wearing course materials. Transactions of the Institutions of Mining and Metallurgy: Section A, 115(4), 140-153.

Van Wieren L. W. and Anderson H. M. 1990. An overview of haul roads at Syncrude Canada 560 Limited. Proc. 2nd International Symposium of Mining Planning and Equipment Selection, Calgary, Balkema, 283-289. 
562 Verdugo R. and Hoz, K. 2006. Strength and stiffness of coarse granular soils. Soil Stress-

563 Strain Behavior: Measurement, Modeling and Analysis Geotechnical Symposium, $564 \quad$ Roma, Italy, March 16-17, 243-252.

565 Wight, J. K., and MacGregor, J. G. 2009. Reinforced Concrete, Mechanics and Design. $5^{\text {th }}$ 566 Edition, Prentice-Hall, Englewood Cliffs, N.J., USA.

$567 \mathrm{Wu} \mathrm{W}$., and Thomson R. 2007. A study of the interaction between a guardrail post and soil 568 during quasi-static and dynamic loading. International Journal of Impact Engineering, $569 \quad 34(5), 833-898$.

570 


\section{List of Figures:}

572 Figure 1: Configuration, wheel loads, and axle loads of CAT 797 truck

573 Figure 2. Loading and boundary conditions for the Mechanistic design approach

574 Figure 3: Variation of vertical strain with change in gravel layer thickness ( $98 \%$ dry density)

575 Figure 4: Variation of vertical strain with change in gravel layer thickness (95\% dry density)

576 Figure 5: Variation of vertical strain with change in gravel layer thickness (92\% dry density)

577 Figure 6: Geometry of the FE model for Design Requirement No. 2

578 Figure 7: Boundary condition and equivalent post-tensioning of the FE model for Design

579 Requirement No. 2

580 Figure 8: FE modelling of the tire components

581 Figure 9: Gravel FE model validation against experimental results

582 Figure 10: Gravel thickness design diagram under static loading without concrete post583 tensioning

584 Figure 11: Gravel thickness design diagram under static loading for an equivalent post585 tensioning stress of $1 \mathrm{MPa}$

586 Figure 12: Gravel thickness design diagram under static loading for an equivalent post587 tensioning stress of $1 \mathrm{MPa}$

588 Figure 13: Geometry of the FE model for Design Requirement No. 3

589 Figure 14: Tensile stress history response due to vehicle braking 590 

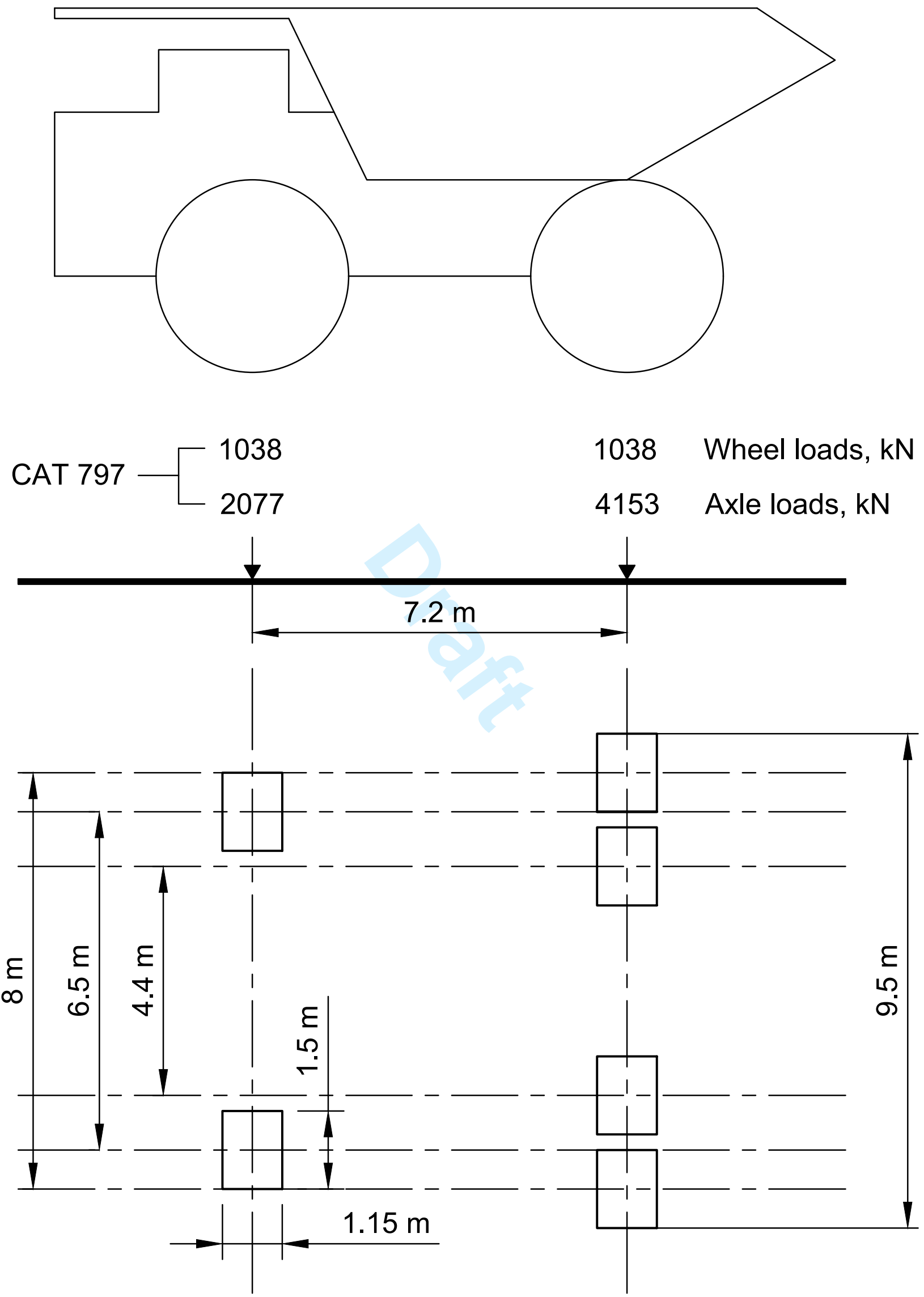


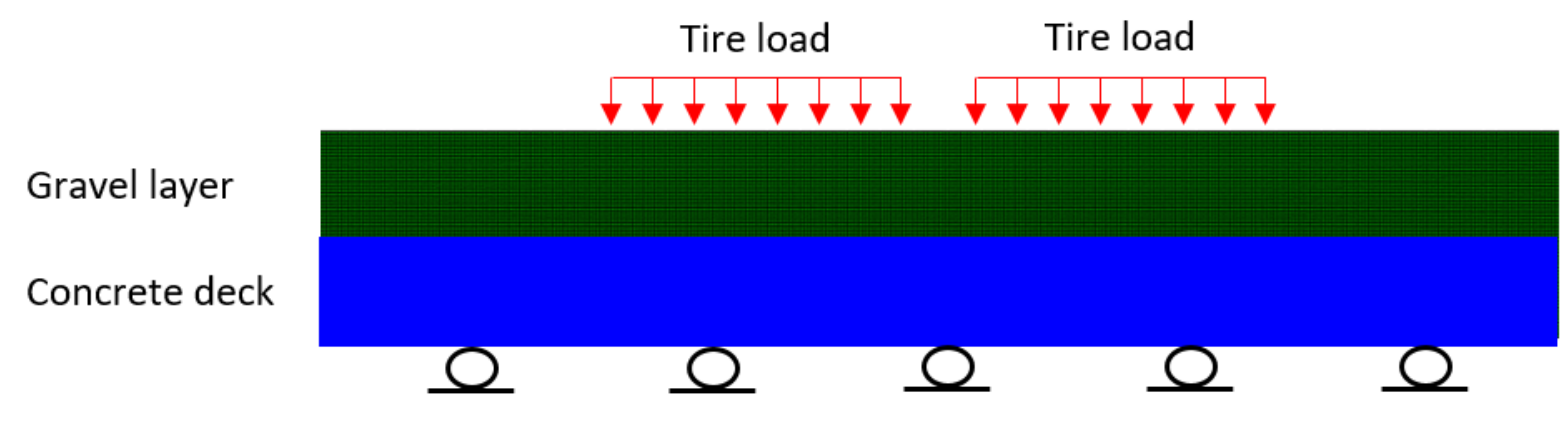




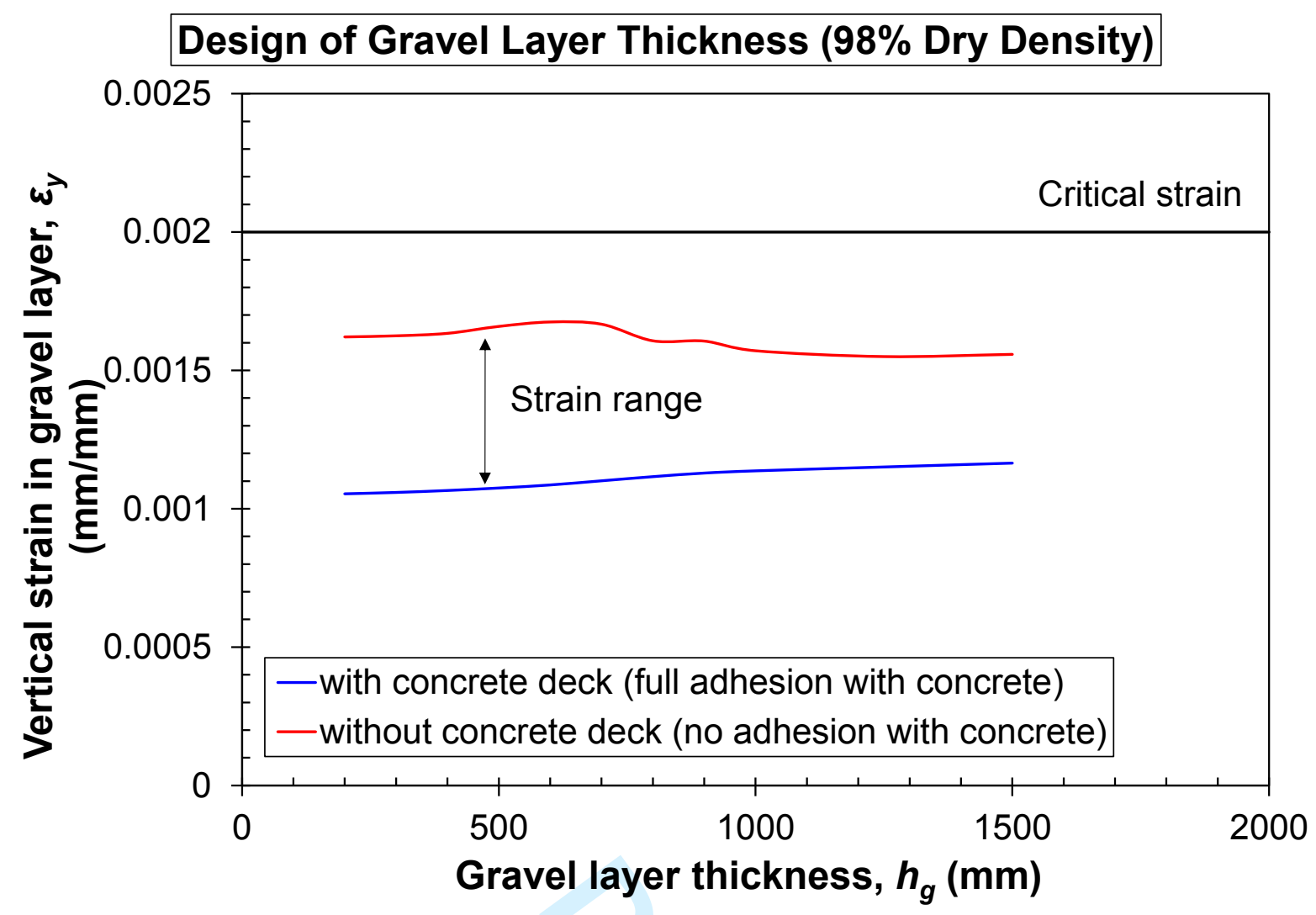




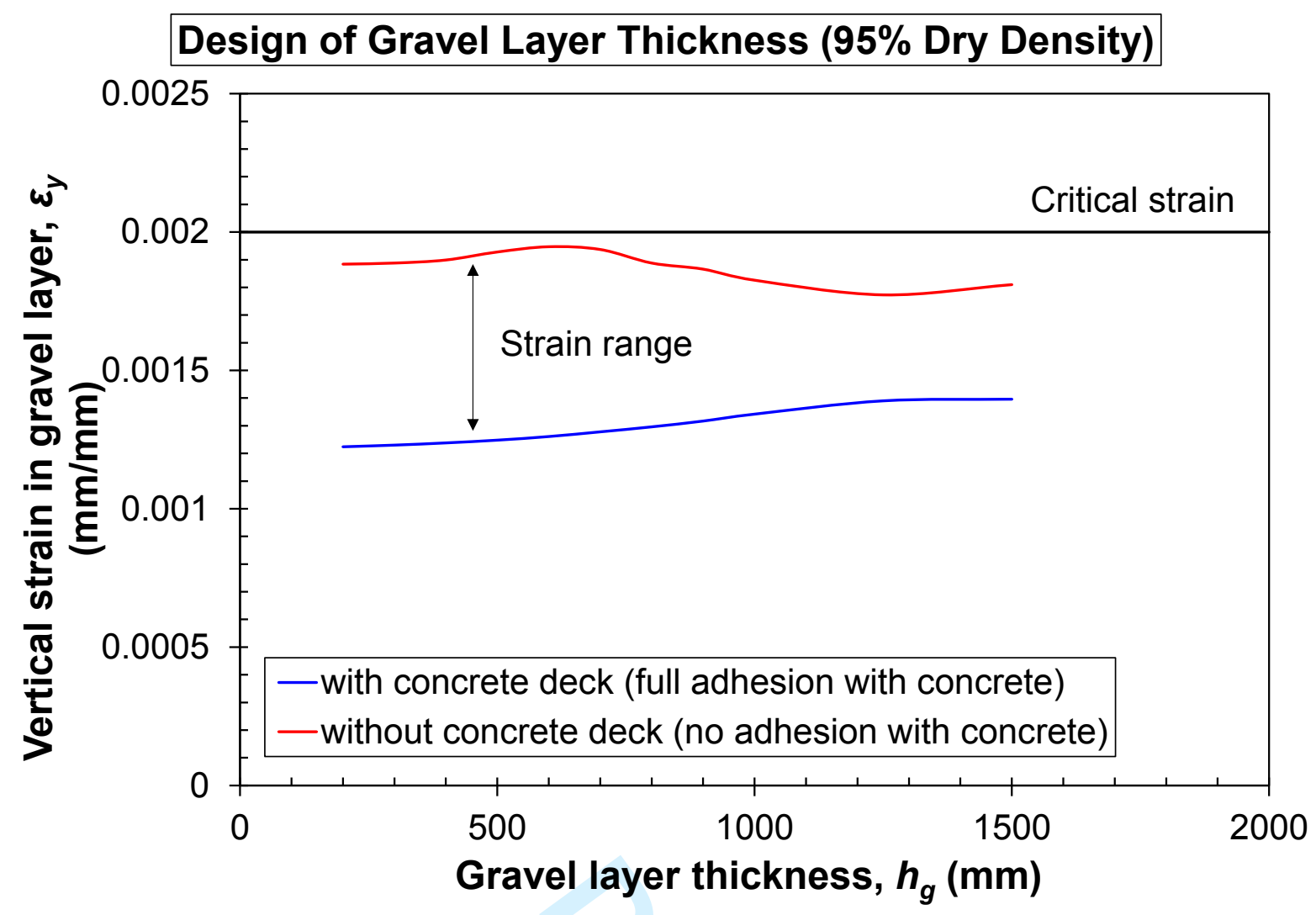




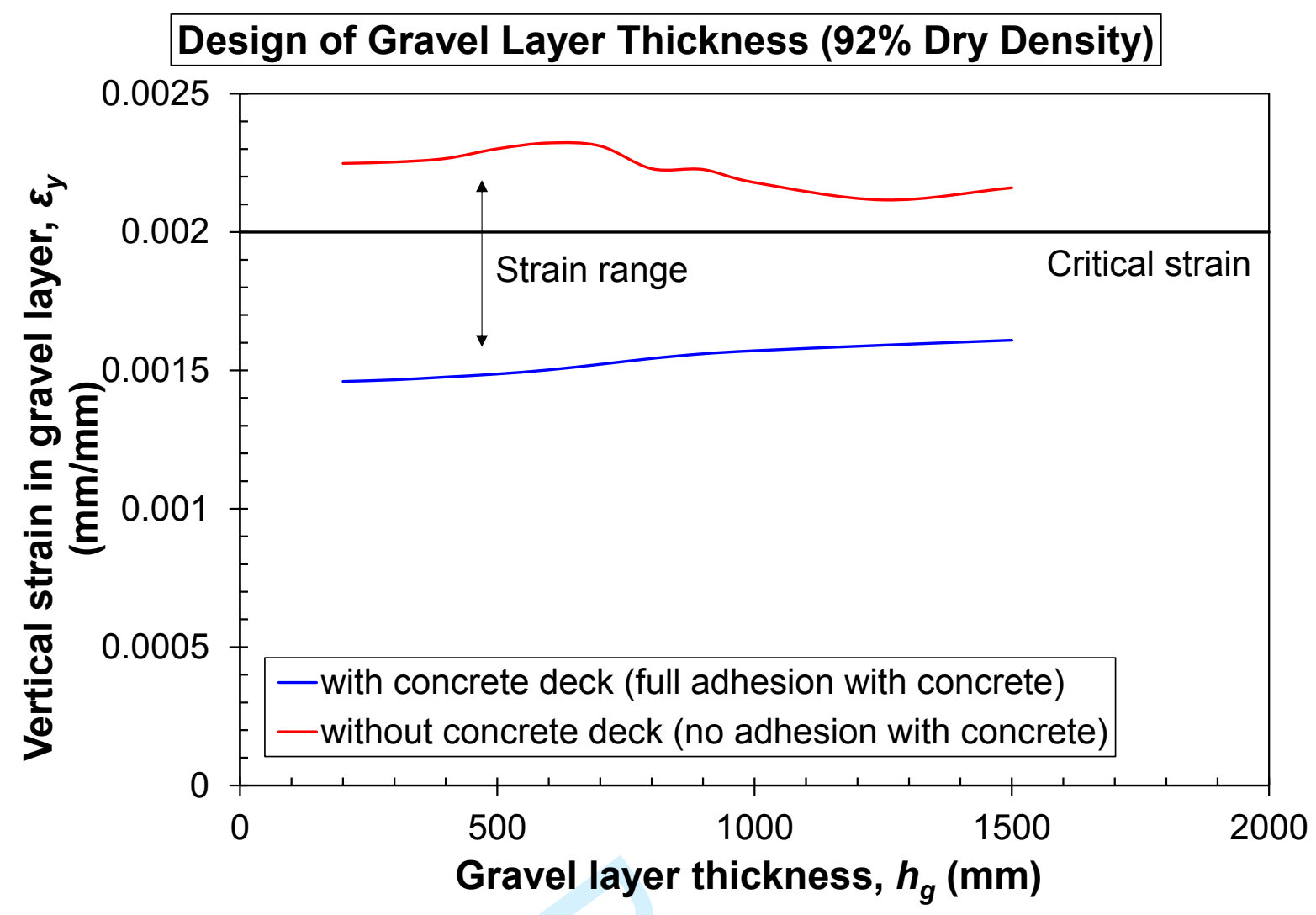




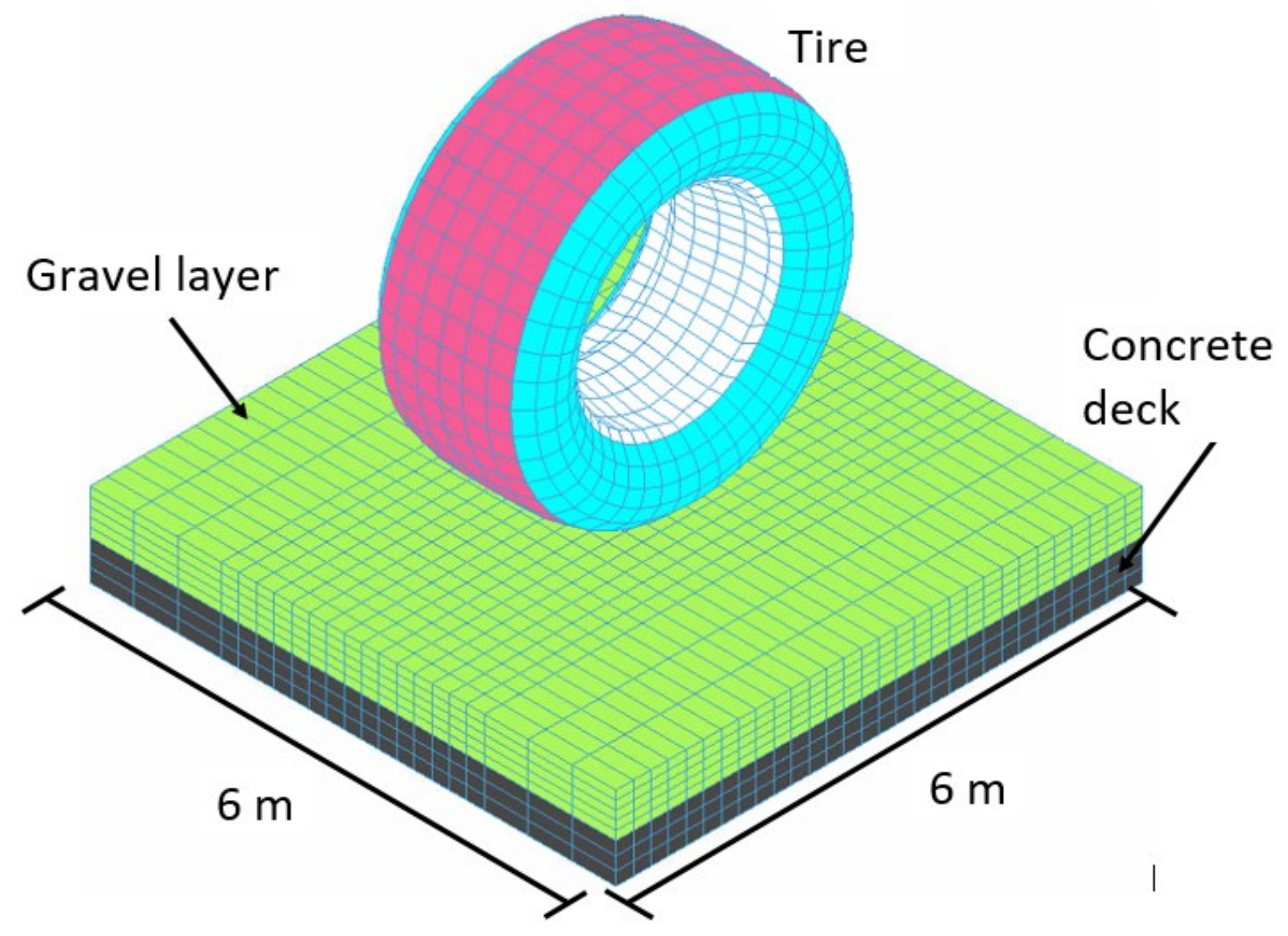




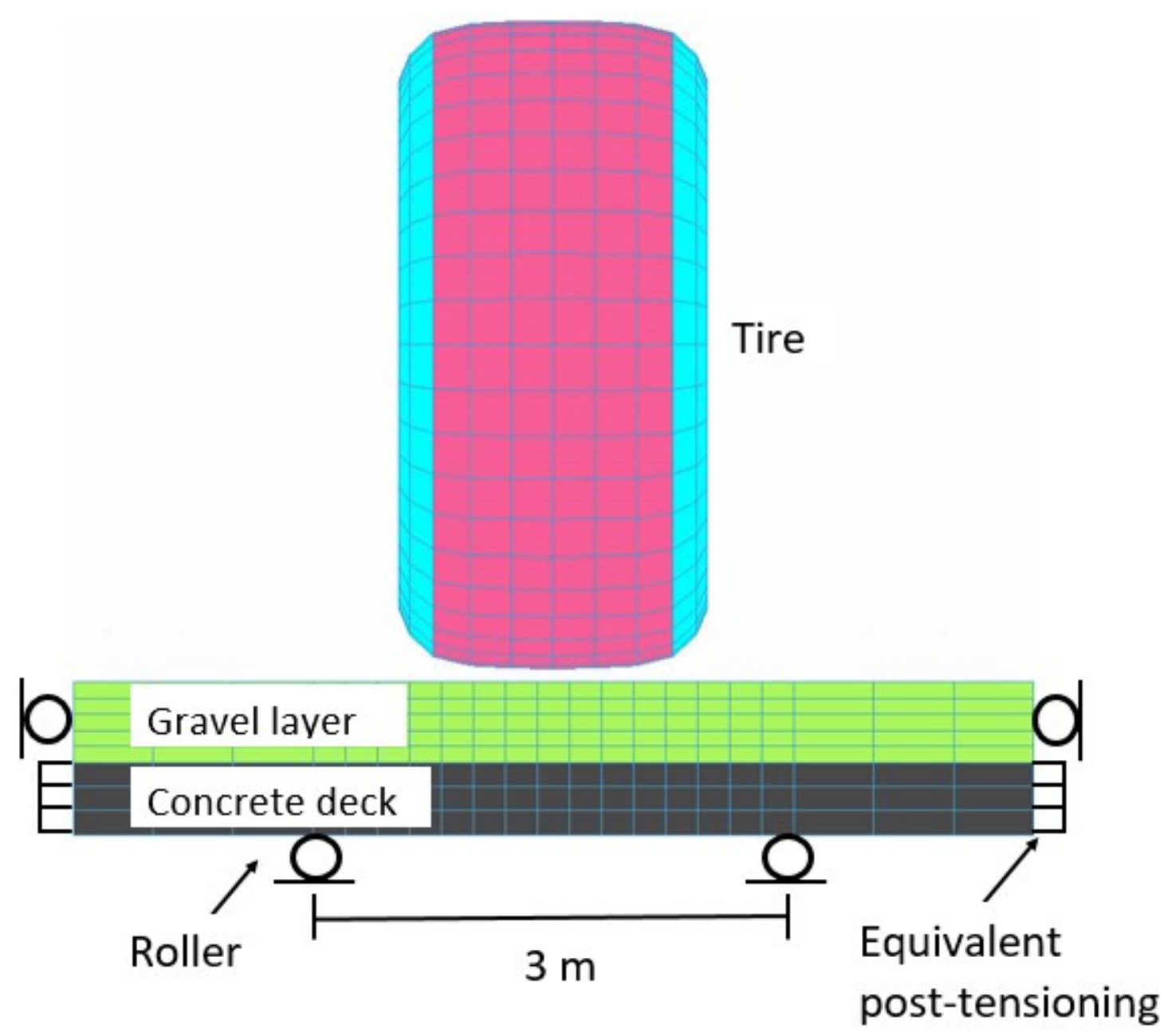




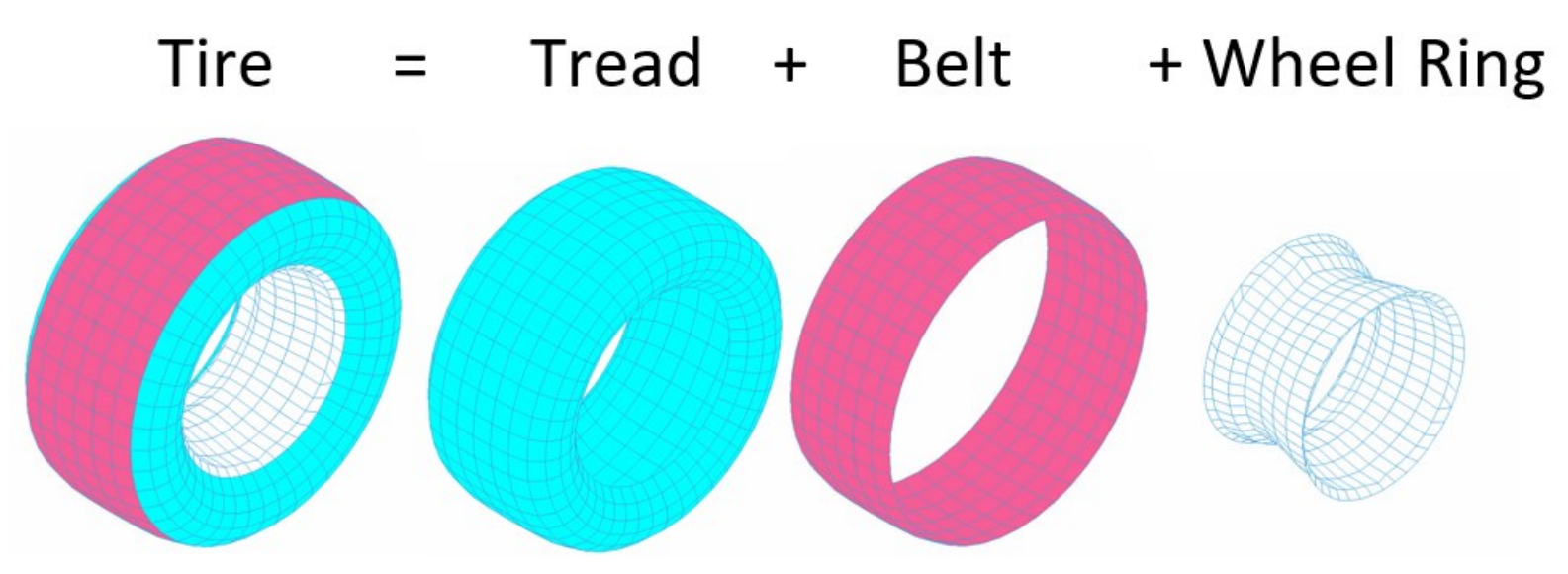




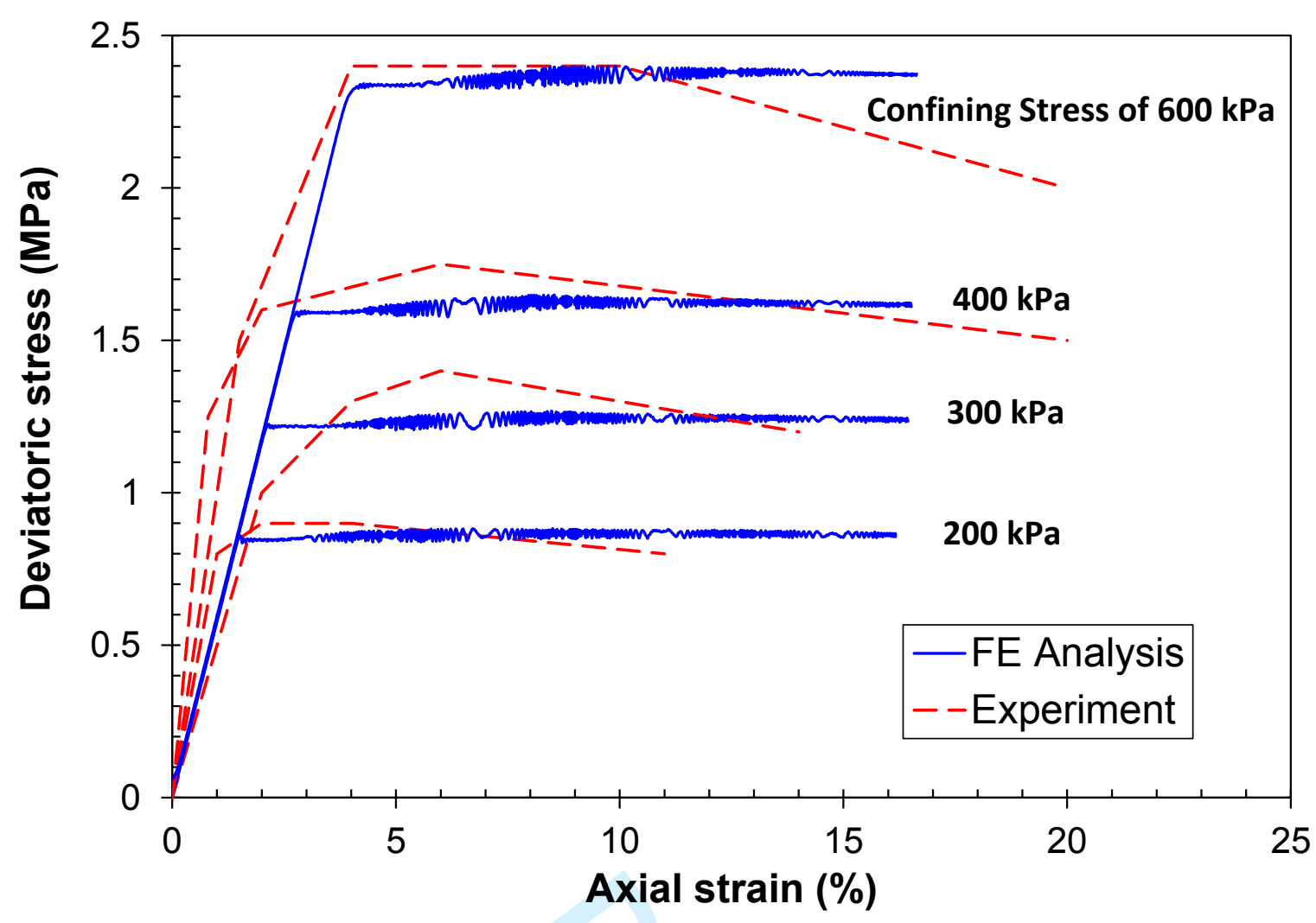




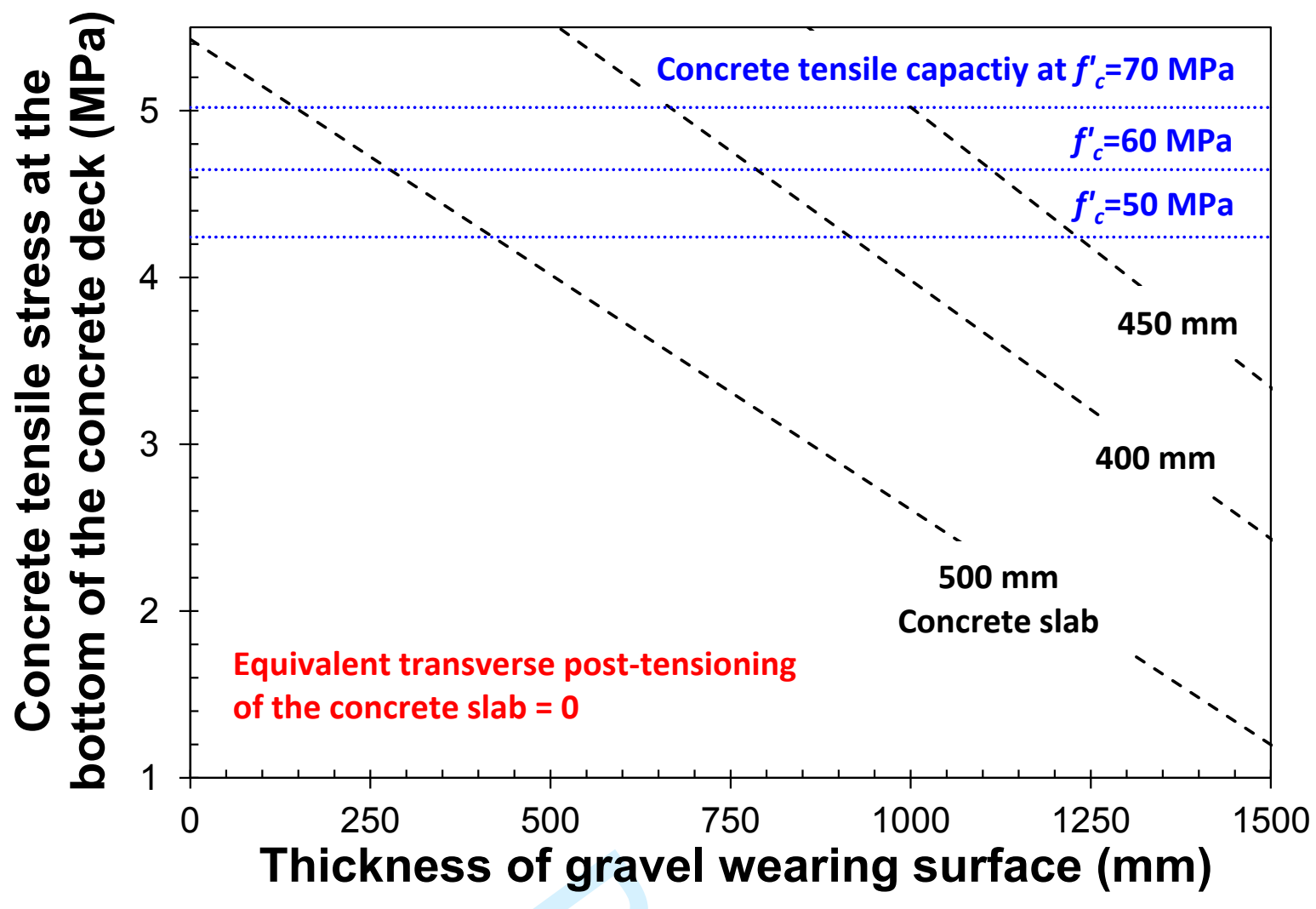




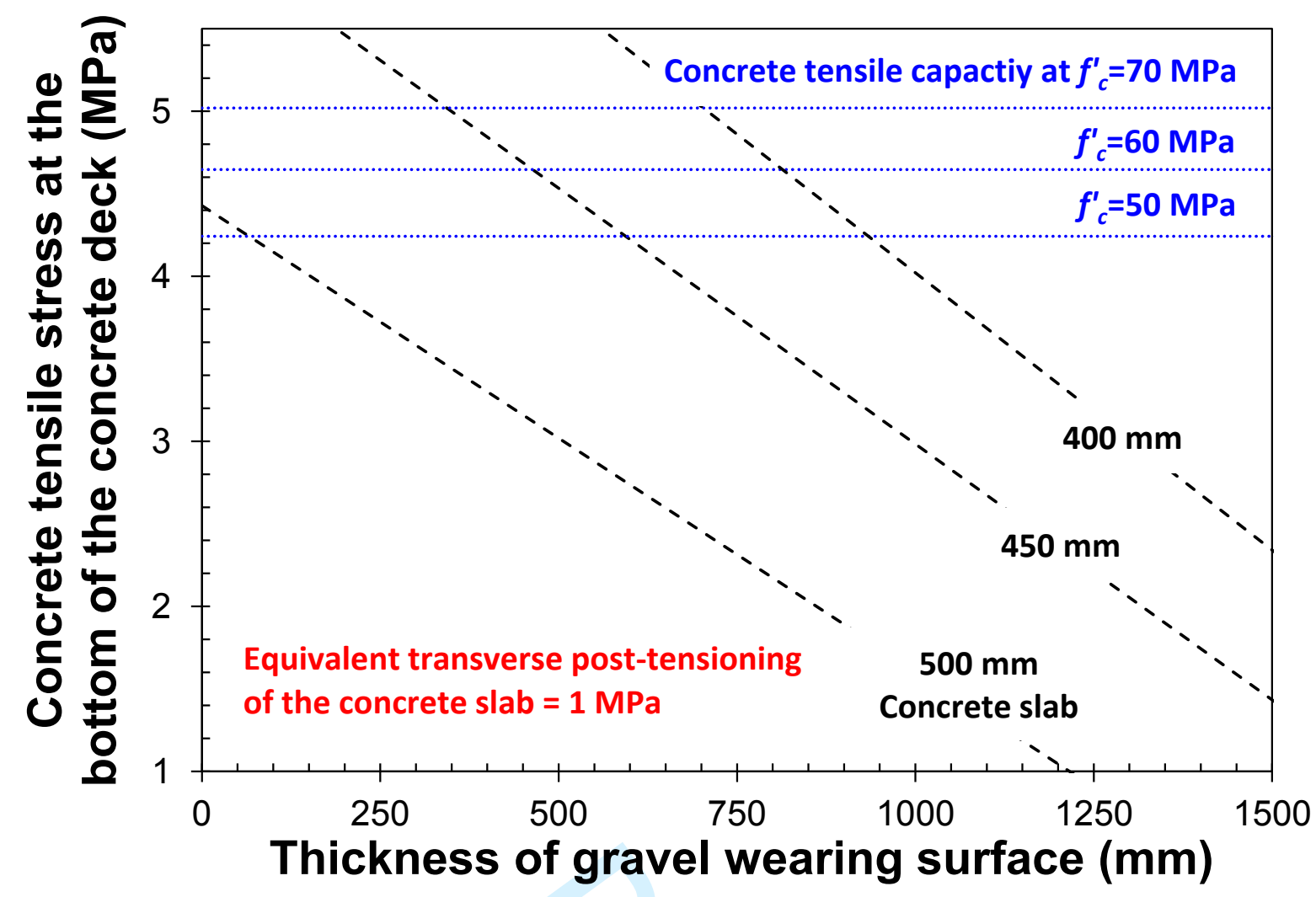




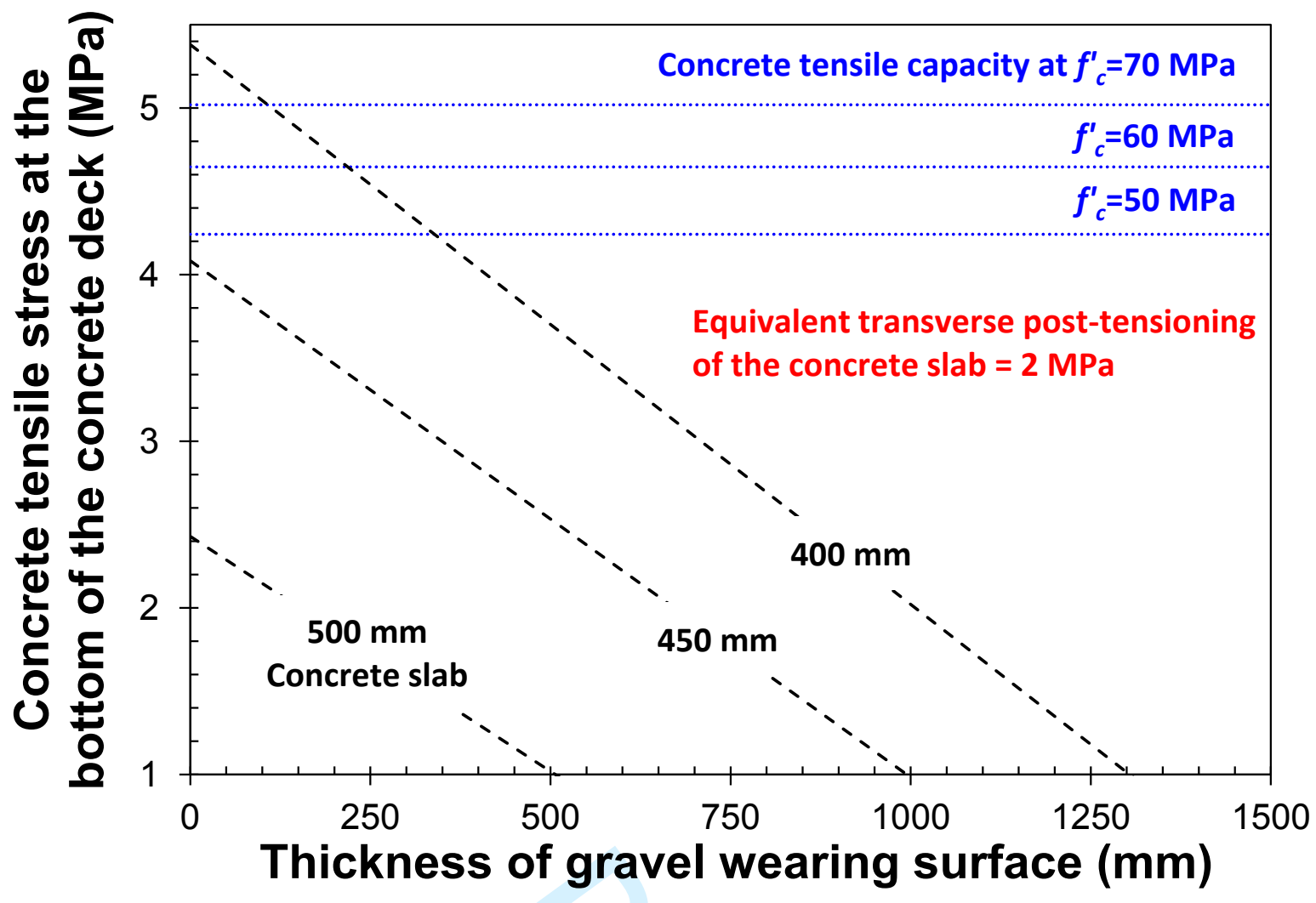




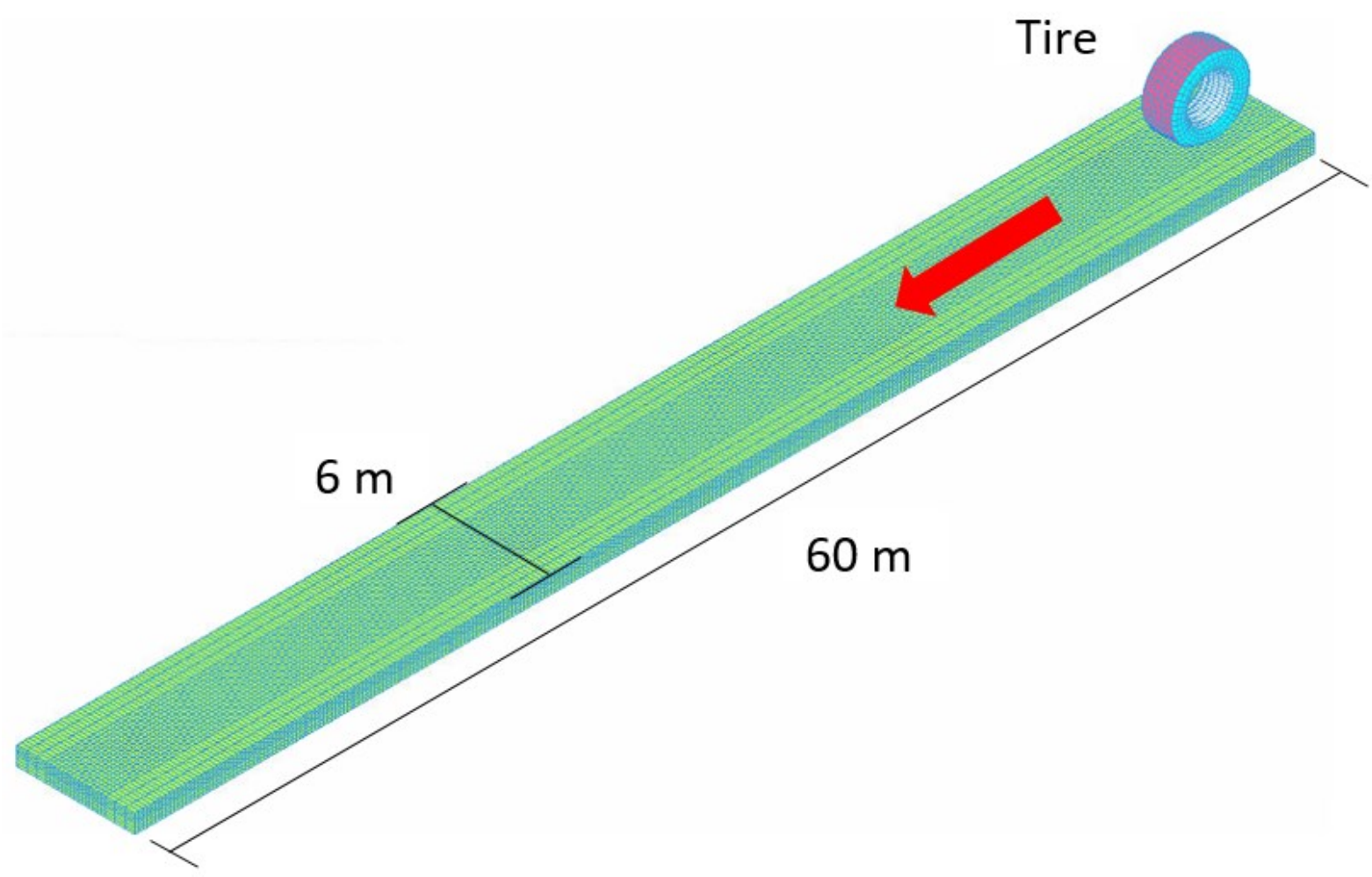



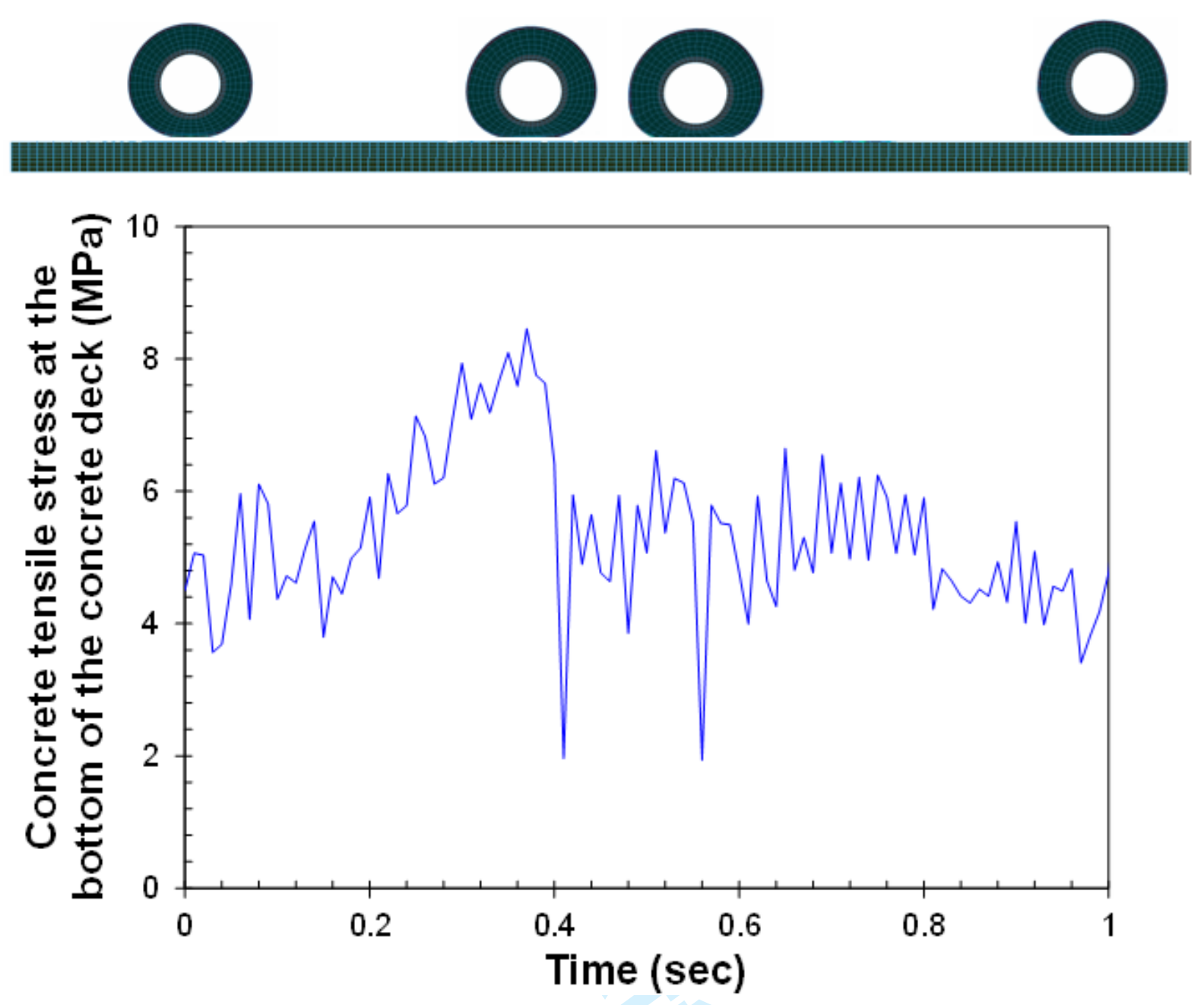